\title{
Abundância Estacional do percevejo-castanho-das-raizes Atarsocoris sp. (Hemiptera: Cydnidae), em pastagens degradadas de Jaguapitã-PR
}

\author{
Seasonal abundance of brown burrowing bug Atarsocoris sp. \\ (Hemiptera: Cydnidae), in degraded pasture from Jaguapitã-PR
}

\author{
Émerson Durski Machado de Oliveira ${ }^{1}$; Amarildo Pasini ${ }^{*}$; \\ Inês Cristina Batista Fonseca ${ }^{3}$
}

\begin{abstract}
Resumo
Os percevejos da família Cydnidae, entre eles o Atarsocoris sp., são insetos-praga com ocorrência em várias culturas, acarretando perdas significativas em áreas com grande infestação desse inseto; sendo também muito comuns associados à plantas daninhas. Este trabalho teve como objetivo avaliar a distribuição sazonal do percevejo Atarsocoris sp. em áreas de pastagens degradadas durante um ano. Verificou-se maior ocorrência de ninfas nos meses de janeiro e outubro, coincidindo com as épocas de maiores precipitações pluviométricas, como consequência, maior umidade no solo. Com relação aos adultos, não acompanharam essa tendência, embora os maiores e menores números de adultos coletados foram nos meses subsequentes aos com maiores e menores números de ninfas, em especiais as ninfas grandes de $4^{\circ}$ e $5^{\circ}$ ínstar.
\end{abstract}

Palavras-chave: Insecta, pastagens degradadas, Scaptocoris castanea

\begin{abstract}
The stinkbugs of the family Cydnidae, as Atarsocoris sp., are pests that occurr in many crops, causing significant losses in areas with high populational rates. They can also be associated with some weed plants. The main goal of this research was to evaluate the seasonal distribution of Atarsocoris sp. in degraded grasslands during one year. It was verified that the highest levels of nymphs occurred in January and October, which corresponded to the highest humidity rates, due to the rainy period. Adults of Atarsocoris sp. did not show the same tendency. Nevertheless, the highest and the lowest populational levels occurred one month after the highest and the lowest populational levels of nymphs, specially when the big nymphs $\left(4^{\text {th }}\right.$ and $5^{\text {th }}$ instar $)$ were considered.
\end{abstract}

Key Words: Insecta, degraded pasture, Scaptocoris castanea

\footnotetext{
Aluno do Programa de Pós-graduação em Agronomia - UEL. E-mail: edurski@uel.br

2 Professor do Departamento Agronomia, UEL, C.P. 6001, CEP 86.051-990, Londrina, PR., Tel. 43 3371-4555, Email: pasini@uel.br

3 Professor do Departamento Agronomia, UEL, C.P. 6001, CEP 86.051-990, Londrina, PR., Tel. 43 3371-4555.

* Autor para correspondência.
} 


\section{Introdução}

O nome popular "percevejo castanho" designa um grupo composto de várias espécies de percevejos de solo, pertencentes à família Cydnidae. Duas espécies desse grupo, Scaptocoris castanea Perty e Atarsocoris brachiariae Becker, vêm causando grandes danos à agropecuária (OLIVEIRA et al. 2000).

O primeiro registro de percevejo-castanho-da-raiz no Brasil ocorreu no final do século XIX, quando Perty descreveu a espécie Scaptocoris castanea Perty, a partir de exemplares procedentes do Piauí (BECKER 1967). Os percevejos deste grupo caracterizam-se por apresentarem o corpo de forma oval, coloração pardo-escura, marrom ou preta; tíbias com espinhos; pernas anteriores geralmente escavatórias (GASSEN, 1989). No Paraná, o percevejo castanho da raiz (Scaptocoris castanea) foi encontrado em Cornélio Procópio e Campo Mourão (FERREIRA; MOSCARDI; SOSA GOMEZ, 1997), e, possivelmente, ele já se encontra disseminado em outras áreas.

Em outros Estados do Brasil, além do percevejo castanho, tem surgido uma outra espécie de percevejo das raízes, descrito e conhecido como percevejo-das-pastagens Atarsocoris brachiariae por Becker (1996), devido à sua grande ocorrência em áreas de pastagens. A autora relata a similaridade de comportamento e biologia entre as espécies Scaptocoris castanea e Atarsocoris brachiariae.

Os percevejos $S$. castanea e $A$. brachiariae são insetos-pragas com ocorrência em várias culturas, destacando-se algodão, soja, milho, arroz e pastagens, provocando danos diretos, pois possuem hábito subterrâneo e sugam as raízes das plantas, acarretando perdas significativas em áreas com grande infestação (ANDRADE; PUZZI, 1951; PUZZI; ANDRADE, 1957; BECKER, 1996; FERREIRA, 1998; OLIVEIRA et al., 1999, 2000). Esta praga tem crescido em importância e sua ocorrência é mais freqüente em solos arenosos (PICANÇO et al., 1999), causando perdas de até $100 \%$ em soja.

A maioria dos registros se limitam à sua ocorrência e aos danos por eles causados, sem que haja re- ferência a aspectos biológicos ou a qualquer medida eficiente de controle ou manejo desses insetos (OLIVEIRA et al., 1999; NAKANO; ROMANO; PESSINI, 2001).

Essas espécies de percevejo ( $S$. castanea e $A$. brachiariae) ocorrem tanto em semeadura direta, como em áreas de manejo convencional de solo. Tanto as ninfas como os adultos sugam raízes de inúmeras plantas cultivadas ou não, inclusive plantas daninhas. Além da sucção da seiva, esses insetos injetam toxinas que impedem o crescimento das plantas, tornando-as amarelas e, em muitos casos, levando-as à morte. $\mathrm{O}$ ataque desta praga ocorre em reboleiras ou focos distribuídos irregularmente na área infestada, podendo o diâmetro médio de cada foco variar de poucos metros até vários hectares (AMARAL et al., 1997).

No seu habitat natural, a cópula e oviposição ocorrem no solo, às vezes em grandes profundidades. A sua localização no solo está relacionada com a umidade e quando exposto à superfície emite um som estridente (AMARAL et al., 1997).

Até o inicio da década de 90 , a ocorrência do $S$. castanea era esporádica em várias regiões e culturas, com alguns surtos maiores nas décadas de 40, 60 e 80 . A partir de 1984, o problema em soja e outras culturas anuais começou ser mais freqüente (PANIZZI, 1997).

Recentemente vem sendo observada uma nova espécie de percevejo castanho do gênero Atarsocoris em pastagens do Paraná, com possibilidade de expansão para culturas agrícolas anuais. Como praticamente não existem informações sobre esse percevejo, este trabalho teve como objetivo avaliar a distribuição sazonal do percevejo Atarsocoris sp., em áreas de pastagens degradadas de Jaguapitã-PR.

\section{Material e Métodos}

O estudo foi realizado em solos de arenito (Latossolo Vermelho) (EMBRAPA, 1999), nos quais predominavam pastagens degradadas de capim Es- 
trela (Synodom sp.), Mato Grosso (Paspalum notatum) e Braquiária (Brachiaria decumbens) na região de Jaguapitã-PR, durante o período de setembro de 2000 a agosto de 2001. (Temperatura média $=21,52^{\circ} \mathrm{C} ; \mathrm{UR}=70,4 \%$ e precipitação mé$\mathrm{dia}=146,42$ milímetros/mês/ano).

As coletas foram mensais, consistindo da retirada 10 amostras de solo, em caminhamento de "zig-zag", e distantes aproximadamente de $10 \mathrm{~m}$ de um ponto a outro. Em cada local retirou-se uma amostra de solo $(20 \times 20 \times 30 \mathrm{~cm})$, com auxílio de uma pá (20 x 20 $\mathrm{cm})$. O solo foi colocado em sacos plásticos e levado ao laboratório para a contagem do número de ninfas (pequenas $<3 \mathrm{~mm}$, médias $3-5 \mathrm{~mm}$ e grandes $>5 \mathrm{~mm}$ ) e adultos do percevejo Atarsocoris sp..

Utilizaram-se os dados de temperatura do $\operatorname{ar}\left({ }^{\circ} \mathrm{C}\right)$ e precipitação pluviométrica $(\mathrm{mm})$, de uma estação experimental, localizada a aproximadamente $7 \mathrm{~km}$ da área de estudo, pertencente à Cooperativa Agropecuária de Rolândia (COROL). Para a confirmação do gênero e espécie desse percevejo, alguns exemplares foram encaminhados para a Dra Jocélia Grazia (UFRS), que confirmou ser uma nova espécie, encontrando-se em fase final de identificação.

As associações entre as variáveis ninfas pequenas, médias e grandes, total de ninfas, total de adultos e total de ninfas + adultos, e as variáveis temperatura e precipitação; foram estudadas através da Análise de Correlação de Pearson. Os dados referentes aos insetos (ninfas e adultos) foram a soma das 10 amostras, e os dados de temperatura e precipitação foram as médias mensais. $O$ coeficiente de Correlação de Pearson foi testetado $\left(\mathrm{H}_{0}: \tilde{\mathrm{n}}=0\right)$ pelo teste $t$ com $5 \%$ de significância.

\section{Resultados e Discussão}

Ninfas e adultos do percevejo Atarsocoris sp. foram encontrados em todas as coletas realizadas durante o ano, com maiores populações nos meses de janeiro e fevereiro, respectivamente (Figuras 1,2 e 4$)$.
O número total de ninfas (pequenas + médias + grandes) foi maior nos meses de janeiro e outubro, onde existiram os maiores índices de precipitação e temperatura. Com o decréscimo desses fatores ocorreu uma redução substancial de ninfas, sendo que estas voltaram a ser encontradas em maior número nos meses de setembro e outubro, quando temperatura e precipitação voltaram a crescer (Figura 1); apesar dessa tendência, não houve correlação positiva significativa, onde o coeficiente de correlação entre número total de ninfas e temperatura foi $r=0,3620(p=$ $0,2476)$, e com precipitação foi $r=0,2483(p=0,4366)$.

Embora, não tenham sido detectados ovos no campo, a maior abundância de ninfas pequenas no mês de janeiro, pode caracterizar que as posturas são efetuadas no mês anterior, ou seja, dezembro (Figura 2).

Ninfas grandes apresentaram correlação positiva com a precipitação pluviométrica ao longo do ano $(\mathrm{r}=0,5952$ e $\mathrm{p}=0,0412)$; as linhas de chuvas com o número de ninfas grandes praticamente se sobrepõem (Figura 3), mostrando uma associação desse fator com os insetos nesse estágio de desenvolvimento. $\mathrm{O}$ pico populacional foi observado no mês de fevereiro com 49 ninfas grandes e $296 \mathrm{~mm}$, em contraste com o mês de agosto com 10 ninfas e $33 \mathrm{~mm}$ de precipitação pluviométrica.

Com relação aos adultos, observou-se as maiores e menores populações nos meses de março e outubro, com 53 e 5 percevejos adultos, respectivamente (Figura 4), onde temperatura e chuva não interferiram diretamente no incremento dessas populações, sendo que o coeficiente de correlação entre adultos e temperatura foi $\mathrm{r}=-0,0213(\mathrm{p}=0,9475)$, e entre adultos e precipitação foi $\mathrm{r}=0,2132(\mathrm{p}=0,4697)$. O maior número de adultos coletados em março se deve ao fato de que em fevereiro ocorreu um aumento no número de ninfas grandes. Conseqüentemente, essas ninfas grandes ( $4^{\circ}$ e $5^{\circ}$ ínstar) se transformaram em adultos, onde o excedente hídrico no solo associado às altas temperaturas, possivelmente proporcionaram condições favoráveis para o aumento da população nesse período. 


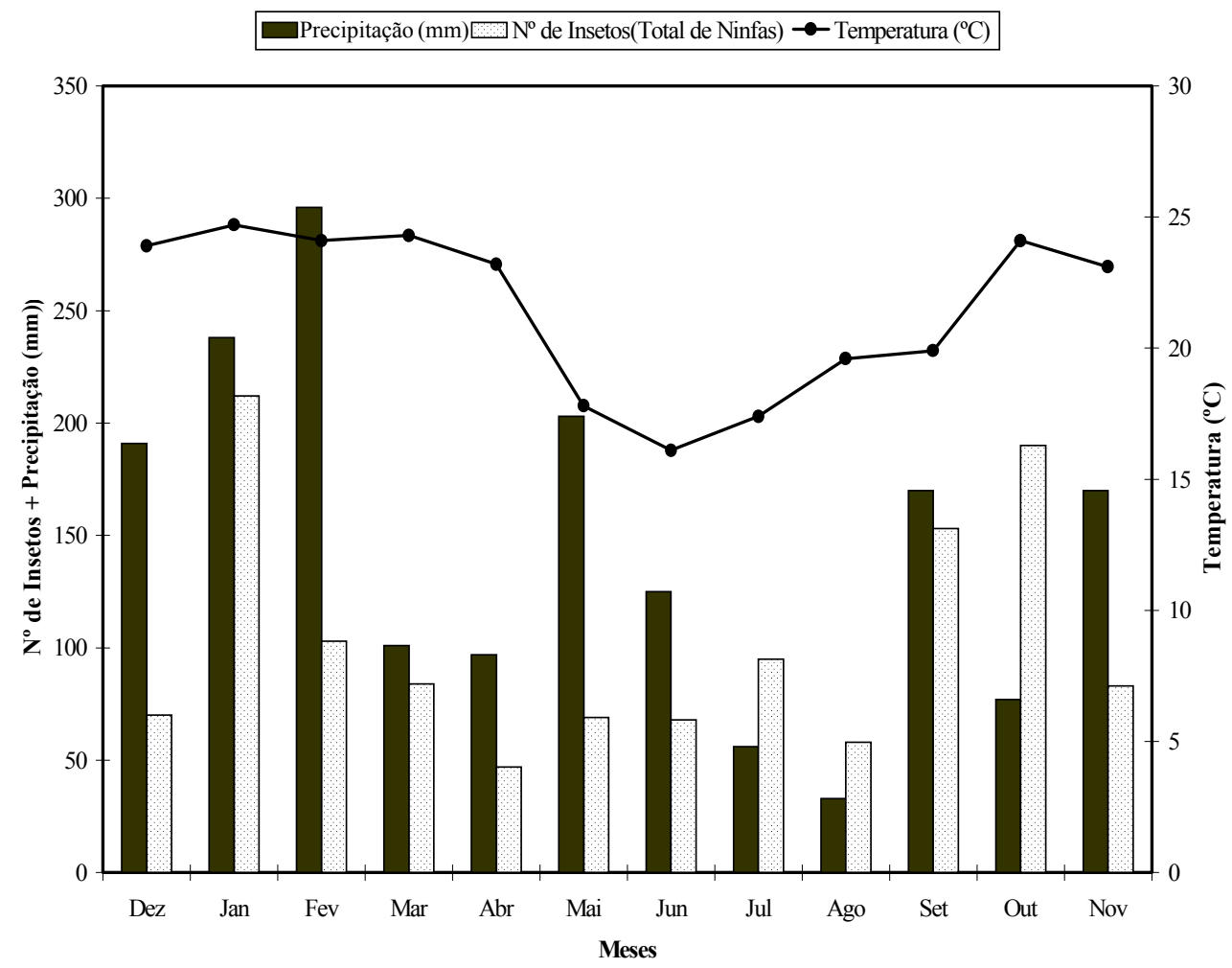

Figura 1 - Abundância Estacional de ninfas de Atarsocoris sp., precipitação pluviométrica (mm) e Temperaturas $\left({ }^{\circ} \mathrm{C}\right) /$ mês, registradas durante o ano de 2000/2001, em Jaguapitã-PR.

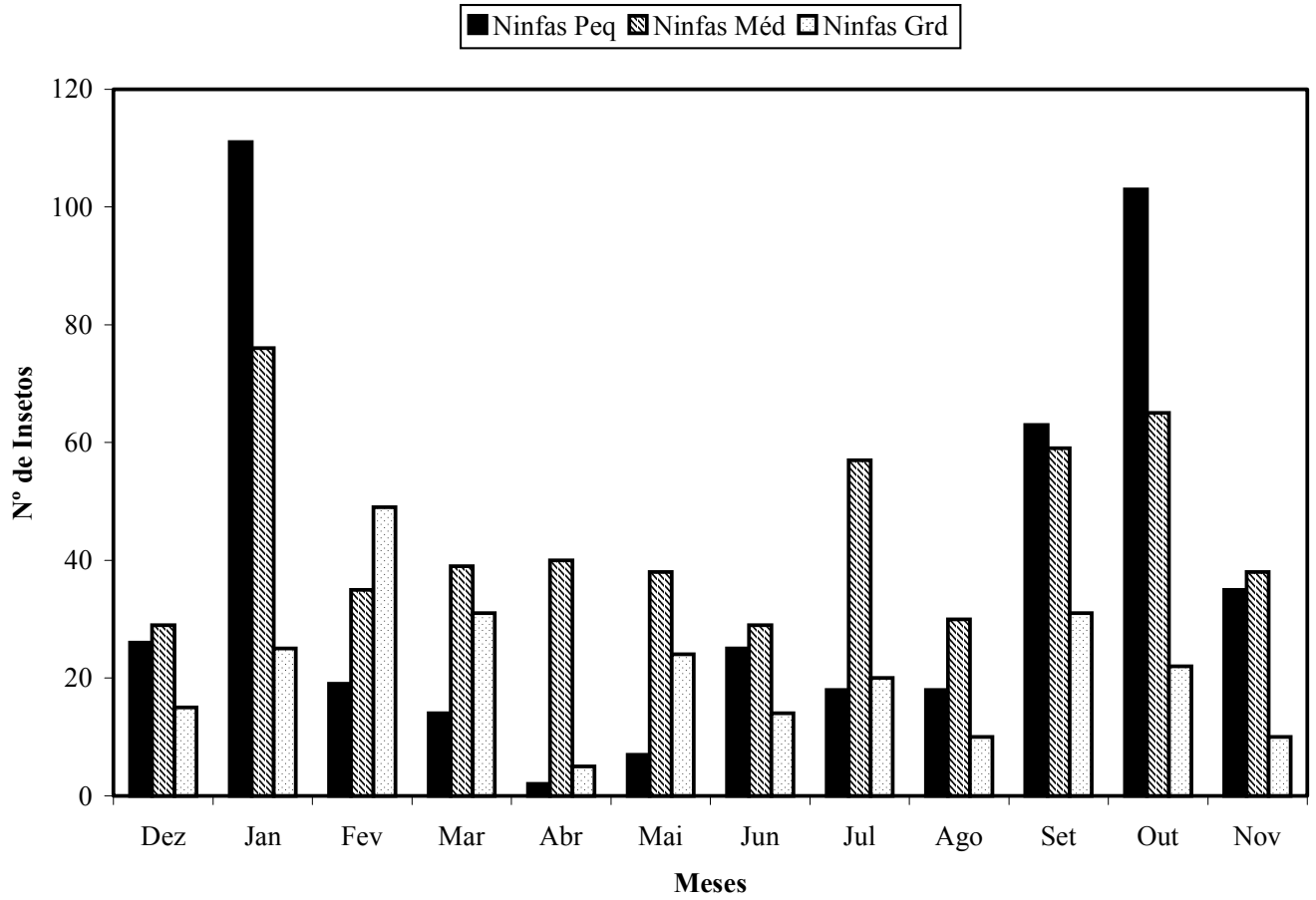

Figura 2 - Abundância Estacional de Ninfas Pequenas, Médias e Grandes de Atarsocoris sp., durante o ano de 2000/ 2001, em Jaguapitã-PR. 


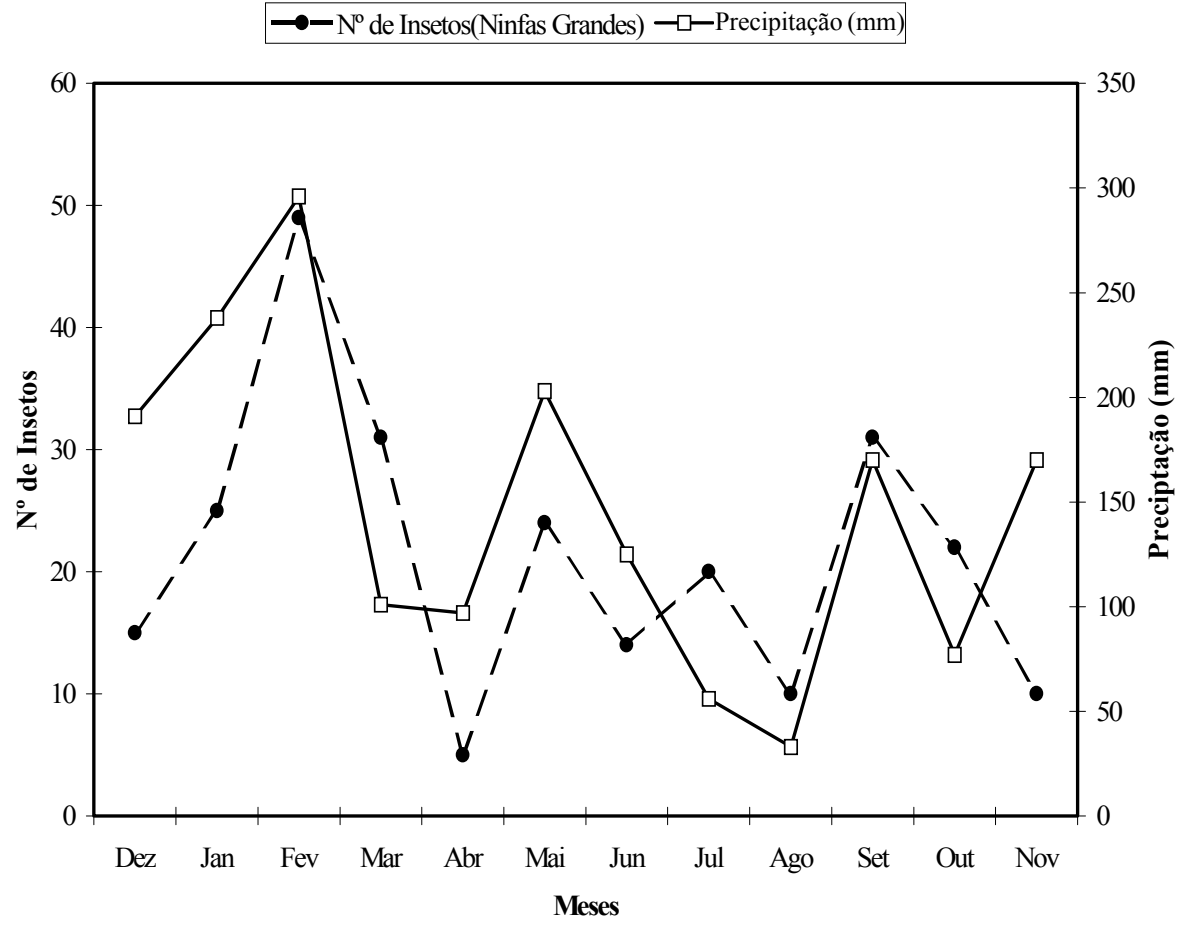

Figura 3 - Abundância Estacional de ninfas grandes ( $>5 \mathrm{~mm})$ de Atarsocoris sp.; e precipitação pluviométrica $(\mathrm{mm}) /$ mês, registradas durante o ano 2000/2001, em Jaguapitã-PR.

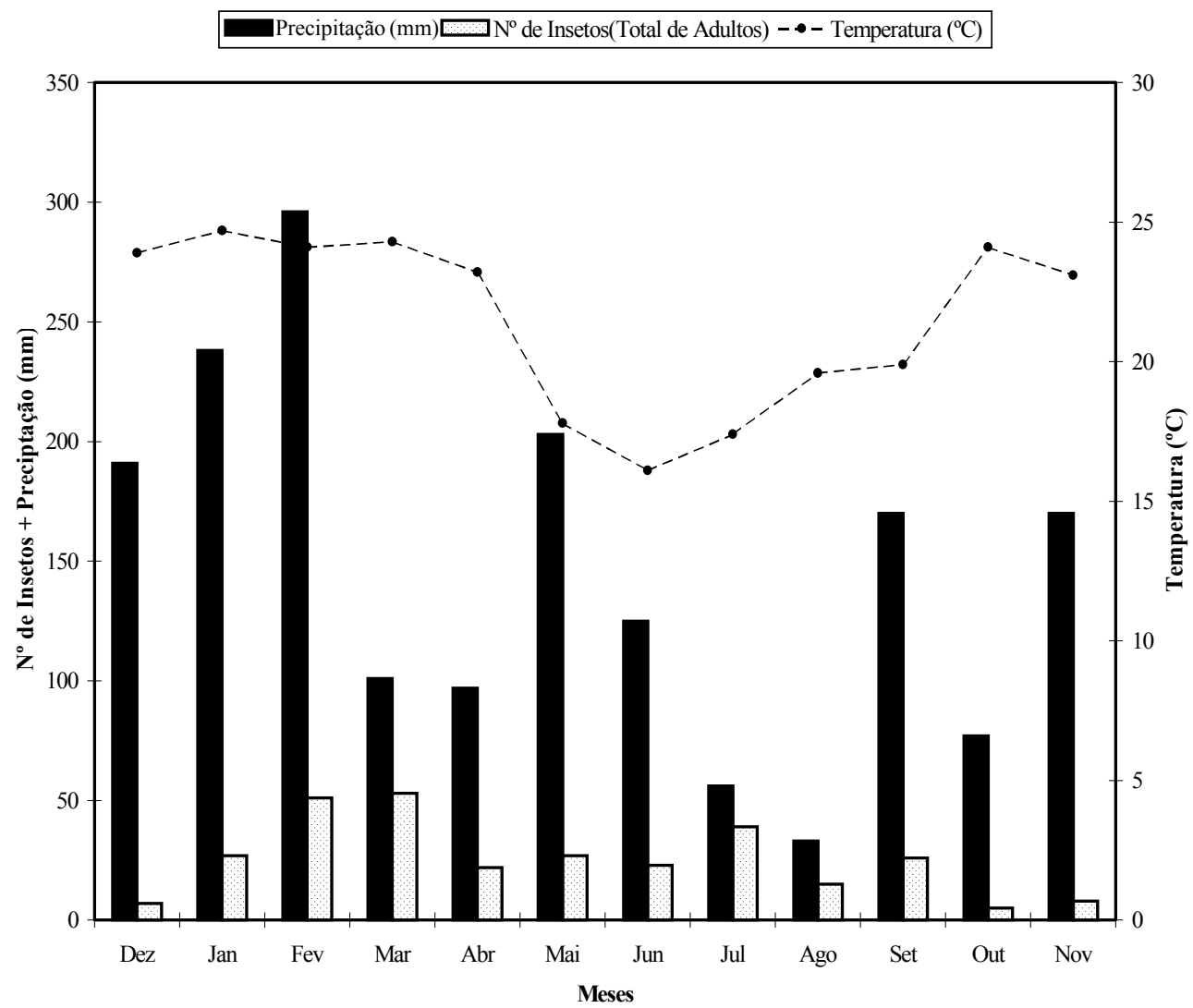

Figura 4 - Abundância Estacional de adultos de Atarsocoris sp., precipitação pluviométrica (mm) e Temperatura $\left({ }^{\circ} \mathrm{C}\right) /$ mês, registradas durante o ano de 2000/2001, em Jaguapitã-PR 
Siloto, Raga e Sato (2001), avaliaram a densidade populacional de ninfas e adultos do percevejo castanho da raiz Scaptocoris castanea em sistemas soja/milho safrinha e pousio durante dois anos no município de Florínea-SP, e obtiveram resultados muito próximos aos encontrados neste trabalho, onde o pico populacional de ninfas foi maior nos meses de maior precipitação (fevereiro). Apesar de serem espécies e sistemas de cultivos diferentes, mas de hábito e comportamento muito semelhantes, a proximidade dos locais de estudo pode ter levado a essa semelhança de resultados.

No entanto, Sales Júnior e Medeiros (2001), avaliando a densidade populacional de ninfas e adultos do percevejo Atarsocoris brachiariae em pastagens de Brachiaria decumbens durante três anos, no município de Rondonópolis-MT, obtiveram resultados mostrando que independentemente da camada de profundidade, as ninfas são encontradas em maiores concentrações na época de deficiência hídrica no solo, enquanto que os adultos são encontrados na época de excedente hídrico. Esse resultado é contrastante ao obtido neste trabalho, visto que as maiores populações de ninfas foram encontradas nos meses de maior excedente hídrico no solo e as maiores populações de adultos foram encontradas justamente quando começava a ocorrer um decréscimo de precipitações, ou seja, redução de água no solo. Provavelmente isso ocorreu por serem regiões com fatores climáticos, preparo do solo, sistemas de cultivos e históricos da área, totalmente diferentes, além do que, apesar de tratar-se de percevejos do mesmo gênero (Atarsocoris), são de espécies diferentes.

Diversos autores relatam que essas espécies de percevejos de raiz são diretamente influenciados pela umidade do solo (GASSEN, 1989; BECKER, 1996; AMARAL et al., 1997; PICANÇO et al.,1999, NAKANO, 2001, SALES JÚNIOR; MEDEIROS, 2001, SILOTO; RAÇA; SATO, 2001), sendo confirmado pelos resultados obtidos neste experimento.

Pelas considerações anteriores, podemos concluir que a umidade do solo, nas condições desse experi- mento, são essenciais para o desenvolvimento do inseto; e mesmo em condições que possam ser desfavoráveis para essa praga, ela se mantém ao longo do ano em todos seus estágios, podendo com isso ter forte poder de proliferação e acarretar sérios prejuízos aos agricultores. Fatores como o cultivo sucessivo, implantação do milho safrinha, grandes áreas de soja, milho e algodão, e pastagens degradadas podem favorecer a expansão dessa praga. Muitas pesquisas sobre esses percevejos devem ser feitas, pois pouco se conhece sobre a biologia, comportamento e controle desse inseto.

\section{Referências}

AMARAL, J. L. et al Castanho das Raízes das Gramíneas e Leguminosas. Revista do Produtor Rural-Famato, v.5, n.58, maio. 1997.

ANDRADE, A. C.; PUZZI, D. Resultados preliminares de experiências para controlar o percevejo castanho em cana de açúcar. Biológico, São Paulo, v.3, p.44-49, 1951.

BECKER, M. Estudos sobre a subfamília Scaptocorianae na região neotropical (Hemiptera: Cydnidae). Arquivos de Zoologia do Estado de São Paulo, São Paulo, v.15, p.291-325, 1967.

BECKER, M. Uma nova espécie de percevejo-castanho (Heteroptera: Cydnidae: Scaptocorinae) praga de pastagens do centro-oeste do Brasil. Anais Sociedade Entomológica do Brasil, Rio de Janeiro, v.25, p.95-102. 1996.

EMBRAPA. Sistema de Classificação de Solos. Brasília: Serviço de Produção de Informação, 1999.

FERREIRA, B. S. C.; MOSCARDI, F.; SOSA-GOMEZ, D. R. Ocorrência do percevejo castanho Scaptocoris castanea Perty em soja em Cornélio Procópio, PR. In: REUNIÃO DE PESQUISA DE SOJA DA REGIÃO SUL, 24., 1996, Anais.... Pelotas: EMBRAPA-CPACT. 1997. p.37

FERREIRA, E. Manual de identificação de pragas do arroz. Santo Antônio de Goiás: EMBRAPA-CNPAF, 1998.

GASSEN, D. N. Insetos subterrâneos prejudiciais às culturas no sul do Brasil. Passo Fundo: EMBRAPACNPT, 1989.

NAKANO, O.; ROMANO, F. C. B.; PESSINI, M. M. de. Pragas de solo. Campinas: ESALQ/USP, 2001.

OLIVEIRA, L. J. et al. Efeito de diversos inseticidas sobre a população de percevejo castanho da raiz, em soja - 
Sapezal, MT. In: WORSHOP PERCEVEJO CASTANHO DA RAIZ, 1999, Londrina. Ata e Resumos... Londrina: EMBRAPA, p. 60-61.

OLIVEIRA, L. J. et al. Manejo do percevejo castanho da raiz: resultados de pesquisa. In: CONGRESSO TECNOLOGIA E COMPETITIVIDADE DA SOJA NO MERCADO GLOBAL, 2000, Cuiabá. Anais... Cuiabá: EMBRAPA, 2000. p.171-175

PANIZZI, A. R. Entomofauna changes with soybean expansion in Brazil. In: WORLD SOYBEAN RESEARCH CONFERENCE, 5., 1997, Bangkok. Proceedings... Bangkok: Kasetsart University Press, 1997.

PICANÇO, M. et al. Ataque de Atarsocoris brachiariae Becker, uma nova praga das pastagens em Mato Grosso, Brasil. Pesquisa Agropecuária Brasileira, Brasília, v.34, p.885-890, 1999.
PUZZI, D.; ANDRADE, A. C. O “percevejo-castanho"Scaptocoris castaneus (Perty) no Estado de São Paulo. Biológico, São Paulo, v.23, p.157-163, 1957.

SALES JÚNIOR, O.; MEDEIROS, M. O. Percevejo castanho da raiz em pastagens. In: REUNIÃO SUL-BRASILEIRA SOBRE PRAGAS DE SOLO, 8., 2001, Paranapanema. Anais... Paranapanema: Embrapa Soja, 2001.

SILOTO, R. C.; RAGA, A.; SATO, M. E. Incidência de Scaptocoris castanea (Perty, 1833) (Hemiptera: Cydnidae) em duas profundidades no solo, no Vale do Médio. In: REUNIÃO SUL-BRASILEIRA SOBRE PRAGAS DE SOLO, 8., 2001, Paranapanema. Anais... Paranapanema: Embrapa Soja, 2001. 
